\title{
Inhalt
}

Vorwort - IX

1 Das Forschungsfeld der sichtbaren Religion

oder wie die religionswissenschaftliche Perspektive erweitert wird - 1

2 Theoretische Horizonte

oder wie sichtbare Religion erfasst wird - 8

2.1 Emische, mediale und wissenschaftliche Blicke auf Religion - 9

2.2 Sichtbare Religion und die Sprache der Wissenschaft — 17

2.3 Religiöse Bilder $-\mathbf{1 8}$

2.4 Religiöse Blicke, Blicke auf Religion - 24

$2.5 \quad$ Kernthemen sichtbarer Religion - 28

3 Methodische Herausforderungen

oder wie sichtbare Religion untersucht wird - 31

3.1 Kultur als Produkt dynamischer Prozesse - 32

3.2 Kodieren und Dekodieren: zwei Seiten von Kommunikation - 39

3.3 Die Position der Forschenden - 46

$4 \quad$ Bilder der Welt

oder wie religiöse Gesamtansichten repräsentiert werden - 50

4.1 Weltbild als umfassende Orientierung - 52

4.2 Weltbild und visuelle Kommunikation - 56

4.3 Verbildlichung kosmischer Ordnung - $\mathbf{5 7}$

4.4 Der betrachtende Mensch im Weltbild - 64

4.5 Blick, Körper und Raum in religiösen Weltbildern — 69

4.6 Pluralität von Weltbildern -71

5 Das Unsichtbare sichtbar machen oder wie Transzendenz visuell erfahrbar wird - 75

5.1 Begriffsklärung: Transzendenz, Transzendenzen, Transzendieren $-\mathbf{7 8}$

5.2 Repräsentation und Regulierung von Transzendenz - 82

5.3 Identitätsbildung und Regulierung durch sichtbare Transzendenz — $\mathbf{8 9}$

5.4 Transzendenz als Erfahrung einer jenseitigen Welt - 92

5.5 Transzendenz in der Immanenz des Sichtbaren — 97 
6

6.2

6.3

6.4

6.5

Alles unter Kontrolle

$$
\text { oder wie Normativität medial vermittelt wird — } 99
$$

$$
\text { Normativität und sichtbare Religion — } 101
$$

Die Werbewirksamkeit normativer Genderdarstellungen — 102 Repräsentation von normativen Blicken auf Gender — 106 Visuelle Handlungsanweisungen - $\mathbf{1 1 0}$

Normative Macht der Bilder — 117

\section{Sichtbar reguliert}

oder wie Macht inszeniert wird -120

Die (audio-)visuelle Repräsentation von Macht — 121

$$
\text { Macht theoretisch } \mathbf{1 2 2}
$$

Dokumentarische Sicht auf Nebenschauplätze — 128

Denkmäler als Repräsentation von Macht — 138

Sichtbare Religion zwischen Legitimierung von Macht und Widerstand 150

In guter Gesellschaft

oder wie Gemeinschaften sich über Bilder definieren - 153

Zwischen Regulierung und Identität — 159

Hinterfragen kollektiver Stereotypen — 164

Materielles Heilsversprechen an eine Gemeinschaft — 167

Geteilte Bedeutungszuschreibungen auf der visuellen Ebene - 172

\section{Private Ansichten}

oder wie religiöse Bilder das Individuum prägen — 174

Visuelle Repräsentation und individuelle Identitätsprozesse — 175

Materielle Emotionen — 180

Spielend Identität bilden — $\mathbf{1 8 5}$

Individualität, Zeitlichkeit und Materialität — 190

Bilder auf Wanderschaft

oder wie Tradition und Innovation sich gegenseitig bedingen — 193

Wanderungen durch Zeiten, Kulturen und gesellschaftliche Bereiche - 194

Herausfordernde Innovationen in Tradierungsprozessen - 198

Regulierende Blicke auf einen überlieferten Bilderfundus - 203

Transformation und Adaptionsprozesse: eine Zwischenbilanz — 206

Die Bildung von Tradition als kreativer Prozess — 207

Religion im kulturellen Imaginären

oder wie sich Religion aus gemeinsamen Bildern speist - 214

Orientierung in der Vielfalt -214 
11.2 Das kulturelle Imaginäre als theoretische Grundlage für visuelle Kommunikation — 215

11.3 Wiederholung und Innovation als Grundtendenzen - 220

11.4 Mentale und materielle Bilder als konstitutive Dimension der Gesellschaft - 225

11.5 Von individuell und kollektiv herausfordernden Bildern — 229

Literatur -233

Abbildungen -250

Autorinnen -254

Index -255 
